\title{
A novel NSAID derivative, phospho-ibuprofen, prevents AOM-induced colon cancer in rats
}

\author{
NENGTAI OUYANG, PING JI and JENNIE L. WILLIAMS \\ Division of Cancer Prevention, Department of Medicine, Stony Brook University, Stony Brook, NY 11794-8175, USA
}

Received October 7, 2012; Accepted November 23, 2012

DOI: $10.3892 /$ ijo.2012.1756

\begin{abstract}
The cancer chemopreventive properties and gastrointestinal toxicity of ibuprofen are well documented. Modification of existing NSAIDs has improved on the chemopreventive efficacy of this agent and reduced its toxicity. In this study, ibuprofen and a modified derivative (phospho-modified ibuprofen or p-ibuprofen) were used in a chemically induced model of colon cancer. Fisher 344 rats were injected with azoxymethane then treated with either ibuprofen $(500 \mathrm{ppm})$ or p-ibuprofen (900 ppm) for 20 weeks to observe aberrant crypt foci $(\mathrm{ACF})$ or 40 weeks to evaluate tumor incidence and multiplicity. $\beta$-catenin and p65 were measured in colonic tissues by immunofluorescence staining. Equal molar doses of ibuprofen (75 and $670 \mathrm{mg} / \mathrm{kg}$ ) and p-ibuprofen (135 and 1,215 mg/kg) were administered to rats for 7 days to assess acute toxicity. The in vitro effect of $\mathrm{p}$-ibuprofen on $\mathrm{COX}-2$ and $\mathrm{PGE}_{2}$ synthesis, $\beta$-catenin expression and $\mathrm{NF}-\kappa \mathrm{B}$ activity were examined in RAW 264.7 macrophage and HCT 116 colon cancer cells. At week 20, p-ibuprofen and ibuprofen significantly reduced the multiplicity of ACF compared with control ( $\mathrm{p}<0.05) ; 31.2$ and $37.9 \%$, respectively. At week 40, p-ibuprofen and ibuprofen reduced the multiplicity of colon tumors compared with control $(\mathrm{p}<0.01)$ by 47.2 and $56.6 \%$, respectively. Equal molar concentrations of ibuprofen $(670 \mathrm{mg} / \mathrm{kg})$ and $\mathrm{p}$-ibuprofen $(1,215 \mathrm{mg} / \mathrm{kg}$ ) resulted in stomach ulceration in $85.7 \%$ (6 out of 7 ) and $14.3 \%$ ( 1 out of 7 ) of rats, respectively, with $\mathrm{p}<0.01$. Immunofluoresence staining and western blot analysis demonstrated that both ibuprofen and p-ibuprofen suppressed $\beta$-catenin nuclear translocation in colon cancer cells. In addition, p-ibuprofen but not ibuprofen inhibited NF- $\kappa \mathrm{B}$ activation in colon cancer cells. Collectively, these results suggest that p-ibuprofen is a potential effective novel drug for long-term use in colon cancer prevention.
\end{abstract}

Correspondence to: Dr Jennie L. Williams, Division of Cancer Prevention, Department of Medicine, Stony Brook University, Stony Brook, NY 11794-8175, USA

E-mail: jennie.williams@sbumed.org

Key words: non-steroid anti-inflammatory drug, colon cancer, $\mathrm{NF}-\kappa \mathrm{B}$, azoxymethane, COX-2, $\beta$-catenin

\section{Introduction}

Numerous animal studies and clinical trials in cancer have shown that ibuprofen reduces the incidence of and mortality from cancer (1-3). However, adverse effects, such as increased gastrointestinal (GI) ulceration, limit its potential for long-term use. To reduce this side effect, different modifications of ibuprofen have been sythesized and evaluated. These modifications include guiacol ester (4), alkyl- or thio-ester (5), diethylcarbonate (6), 2-formylphenyl ester (7), N-hydroxymethyl-succinimide (8), $\beta$-D-glucopyranoside (9), polymerized-2-hydroxyethylmethacrylate (10), PEG1000-linked chondroitin (11), $\alpha$-methyl, ethyl and propyl glucopyranosides (12), cysteamide (13), L-cysteine ethyl ester (14) and NO-donating moieties (15-17). Although most of these modifications did result in a reduction of GI side effects, only a decreased or similar effect of anti-inflammation or anticancer activity was observed when compared with the parent compound ibuprofen. Recently we developed a phospho-butanol-modified ibuprofen (designated p-ibuprofen, hereinafter), which showed promising increased anticancer activity in vitro and in xenograft tumor models (18-20), elevated anti-inflammation in an arthritis rat model (21), and reduced GI toxic side effects. Xie et al (20) found that p-ibuprofen is minimally metabolized by cultured cells, but extensively metabolized by mouse liver microsomes, undergoing regioselective oxidation to produce 1-OH-p-ibuprofen and carboxyl-p-ibuprofen, which can be hydrolyzed to the parent metabolites, 1-OH-ibuprofen and carboxyl-ibuprofen, respectively. These results indicate that the anticancer effect of p-ibuprofen may be different between in vitro and in vivo situations. Therefore, additional in vivo studies are necessary to evaluate the chemopreventive effect of p-ibuprofen before it can be considered for human clinical trials.

Both COX-2 dependent and independent pathways may be involved in the mechanism by which NSAIDs prevent cancer. It remains to be fully elucidated whether p-ibuprofen suppresses cancer growth by the COX-2 pathway or COX-2 independent pathways. Previous studies (19-21) have suggested that oxidative stress mediated apoptosis, reduced inflammatory cytokines, and inhibition of NF- $\mathrm{KB}$ activation are involved in the mechanism of its action. Wong et al (22) reported that both p-ibuprofen and ibuprofen can be hydrolyzed by carboxylesterases in the liver, and that the integrity of the drug is critical for anticancer activity. p-Ibuprofen's reduced GI toxicity may be a result of the modification of the phospho-group (with the $\mathrm{COOH}$-group), 
which is known to account for the GI toxicity of the conventional NSAIDs (23).

In this study, we tested the chemopreventive effect of p-ibuprofen in a long-term use scenario using a chemicalinduced colon cancer model in rats. The acute and chronic toxicities of $\mathrm{p}$-ibuprofen were evaluated in rats. In additon, the effect of p-ibuprofen on COX-2-dependent and -independent pathways, including $\beta$-catening and $\mathrm{NF}-\kappa \mathrm{B}$ pathways, were studied in vitro.

\section{Materials and methods}

Drugs. Ibuprofen was purchased from Sigma (St. Louis, MO). Phospho-butanol-ibuprofen was purchased from Chem-Master International Inc. (East Setauket, NY). The chemical structure is shown in Fig. 1A. The purity of synthetized drug p-ibuprofen is $>99 \%$.

Animal model and treatments. Fisher 344 male rats (135) (Harlan Sprague Dawley, Indianapolis, IN), 3-4 weeks old with an initial average body weight of $90 \mathrm{~g}$, were acclimated for 1 week, divided into 6 groups: groups 1, 3 and 5 were given saline as control, 15 rats per group; and groups 2 , 4 and 6 were given carcinogen, 30 rats per group. Animals received either saline or carcinogen (azoxymethane, AOM, at $15 \mathrm{mg} / \mathrm{kg}$ ) by subcutaneous injection, once a week for two weeks. Drug administration was also initiated in rats via diet 10 days before subcutaneous injections: vehicle for groups 1 and 2; ibuprofen, 500 ppm, for groups 3 and 4; and phosphoibuprofen (p-ibuprofen, the same hereinafter), 900 ppm (equal molar dose with ibuprofen), for groups 5 and 6 . All drugs were administered up until the end of the experiment as shown in Fig. 1B. Animals were housed and maintained according to the approved standards of Stony Brook University Institutional Animal Care and Use Committee. Animals were housed two per plastic cage with sawdust bedding and were kept under standard laboratory conditions (room temperature, $22 \pm 2{ }^{\circ} \mathrm{C}$; relative humidity, $50 \pm 5 \%$; light/dark cycle $12 / 12$ h). All animals had access to food and tap water ad libitum. Rats were observed daily and weighed once a week. Half of the rats from each group were euthanized at week 20 and analyzed for aberrant crypt foci (ACF). Blood was collected for pharmacokinetic (PK) analysis. The remaining rats were euthanized at week 40 and colons were dissected and analyzed for aberrant crypt foci (ACF) and tumors. Heart, lung, liver, stomach and kidney were collected from animals in the control groups and fixed in buffered-formalin for histological analysis of potential toxic effects.

ACF analysis. For animals sacrificed at week 20, ACF were counted in colon tissues as previously described (24). Briefly, the colons were removed, rinsed with ice-cold phosphate-buffered saline (PBS), placed on filter paper, opened longitudinally, and fixed in $10 \%$ buffered formalin for $24 \mathrm{~h}$. Then colon tissues were stained with $0.2 \%$ methylene blue for 3 to $5 \mathrm{~min}$. The number of ACF per colon was determined by microscopic examination. ACF were distinguished from surrounding normal crypts by increased size, thickened epithelial cell lining, and enlarged cryptal area relative to surrounding normal crypts as shown in Fig. 2A.
Tumor analysis. At week 40, the remaining animals were sacrificed by $\mathrm{CO}_{2}$ asphyxiation. Colons were removed, opened longitudinally, and rinsed with PBS. Tumors were counted and both long-diameter by short-diameter were measured to calculate tumor size. After measurements were recorded, one half of each colon sample was frozen in liquid nitrogen and stored at $-80^{\circ} \mathrm{C}$ for further analyses. The remaining half of each colon was fixed in buffered formalin for histopathology processing. Briefly, colon tissue with tumors were equally cut into 10 pieces, and embedded in paraffin blocks. Sections $(4 \mu \mathrm{m})$ were stained with hematoxylin and eosin to determine histopathology by pathologist, or stained by immunohistochemistry and immunofluorescence for mechanism study.

Toxicity. Thirty-five Fisher 344 rats (Harlan Sprague Dawley), male, 8-9 weeks old, were divided into 5 groups $(7$ rats per group) and treated with the following: group 1, vehicle; group 2, ibuprofen $75 \mathrm{mg} / \mathrm{kg}$ of body weight; group 3, ibuprofen $670 \mathrm{mg} /$ $\mathrm{kg}$; group 4, p-ibuprofen $135 \mathrm{mg} / \mathrm{kg}$; and group 5, p-ibuprofen $1,215 \mathrm{mg} / \mathrm{kg}$. The drugs were administered by gavage, once a day for 7 days. Animals were housed under standard conditions and euthanized by $\mathrm{CO}_{2}$ asphyxiation $1 \mathrm{~h}$ after final drug administration. Blood was collected for PK studies. Stomach, small intestine and colon were checked for ulcers under magnification lens then fixed with $10 \%$ buffered formalin for histology. Heart, liver, lung and kidney were collected for toxicity analyses.

Pharmacokinetics and HPLC analysis. The blood samples collected from animals sacrificed at week 20 and from the toxicity study with low dose treatment were used for the PK study. Briefly, ibuprofen and its metabolites were extracted by adding a 2-fold volume of acetonitrile. After centrifugation for $10 \mathrm{~min}$ at $5,000 \mathrm{x} \mathrm{g}$, the supernatants were subjected to HPLC analysis. The HPLC system consisted of a Waters Alliance 2695 Separations Module equipped with a Waters 2998 photodiode array detector (220 nm) (Waters, Milford, MA) and a Thermo BDS Hypersil C18 column (150x4.6 mm, particle size $3 \mu \mathrm{m})$ (Thermo Fisher Scientific, Waltham, MA). The mobile phase followed a gradient between buffer A [formic acid, acetonitrile, $\mathrm{H}_{2} \mathrm{O}$ (95:4.9: 0.1 v/v/v)] and buffer B (acetonitrile).

Prostaglandin E2 $\left(\mathrm{PGE}_{2}\right)$ and $\mathrm{COX}-2$ in vitro. To evaluate the inhibitory effect of ibuprofen or p-ibuprofen on COX-2, RAW 264.7 macrophages were pre-treated with ibuprofen or p-ibuprofen, $130 \mu \mathrm{M}$, for $12 \mathrm{~h}$, then incubated with LPS, $100 \mathrm{ng} /$ $\mathrm{ml}$, overnight. The cells were collected for COX-2 measurement and analyzed by western blotting. Levels of $\mathrm{PGE}_{2}$ in cell culture media were determined using a commercially available immunoassay kit according to the manufacturer's instructions. Briefly, $1.5 \times 10^{6}$ Raw 264.7 macrophages were pre-incubated with ibuprofen or p-ibuprofen, $130 \mu \mathrm{M}$, for $12 \mathrm{~h}$, followed by LPS (100 ng/ml) overnight. The cultured media were collected to measure $\mathrm{PGE}_{2}$ level using an ELISA kit (Cayman Chemical, Ann Arbor, MI).

Immunofluorescent double staining. Paraffin-embedded sections were deparaffinized, rehydrated and microwave heated for $15 \mathrm{~min}$ in $0.01 \mathrm{~mol} / \mathrm{l}$ citrate buffer $(\mathrm{pH} 6.0$ ) for antigen retrieval. Tissue sections were then incubated with $5 \%$ donkey serum for $30 \mathrm{~min}$, then treated with primary antibodies, rabbit 
A<smiles>CCOP(=O)(O)OCCCCOC(=O)C(C)c1ccc(CC(C)C)cc1</smiles>

p-IBU<smiles>CC(C)Cc1ccc(C(C)C(=O)O)cc1</smiles>

Ibuprofen

\section{B}
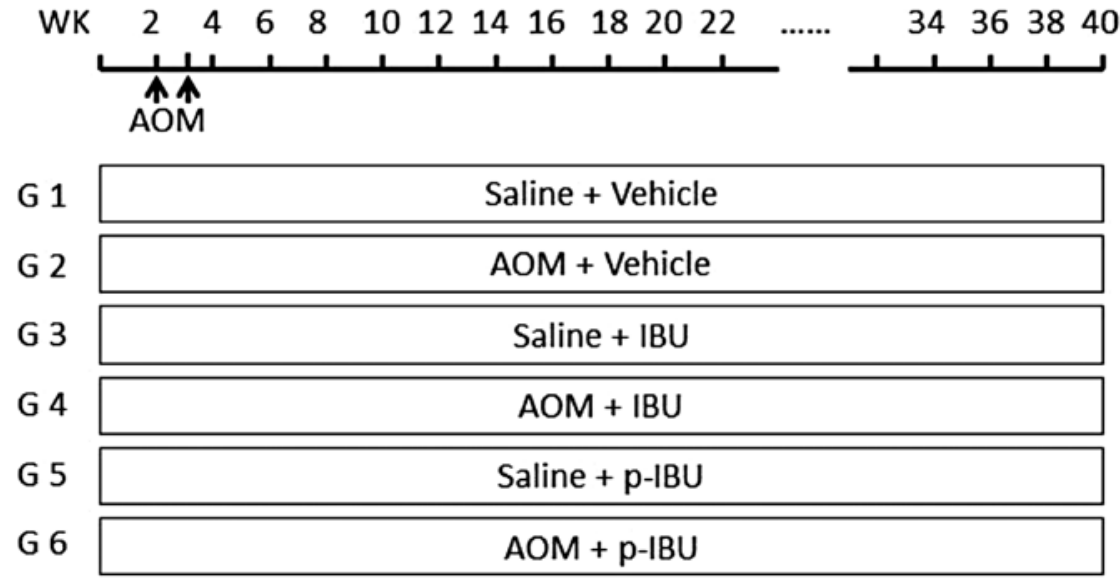

Figure 1. Chemical structure of p-IBU and design of in vivo experiment. (A) The chemical structures of p-IBU and parent molecule IBU are presented in the top panel. (B) As described in Materials and methods, animals were placed on a control diet or study diet (food supplemented with of IBU or equal molar concentration of p-IBU) for 10 days prior to subcutaneous injection with $15 \mathrm{mg} / \mathrm{kg}$ AOM, once a week for two weeks (bottom panel).

anti-phospho-p65, ser276 (Cell Signaling, Danvers, MA) and mouse anti- $\beta$-catenin (Millipore, Temecula, CA) or control $\mathrm{IgG}$, at $4^{\circ} \mathrm{C}$ overnight. After washing with PBS $3 \times 5 \mathrm{~min}$, the secondary donkey anti-mouse $\operatorname{IgG}$ and donkey anti-rabbit IgG conjugated with fluorescents were added and incubated at room temperature for $1 \mathrm{~h}$. Slides were washed thrice with PBS, mounted with media and observed under a fluorescence microscope.

Cell culture. RAW 264.7 macrophage (mouse leukemic moncyte) and HCT 116 colon cancer cell lines were purchased from American Type Culture Collection (Manassas, VA) and cultured in DMEM or RPMI-1640 medium, respectively.

Western blot analysis. Whole cell extracts were obtained by lysing cells in RIPA buffer [50 mM Tris- $\mathrm{HCl}$ (pH 7.4), $150 \mathrm{mM}$ $\mathrm{NaCl}, 1 \mathrm{mM} \mathrm{Na}{ }_{2}$ EDTA, $1 \mathrm{mM}$ phenylmethylsulfonyl fluoride (PMSF), 1\% NP-40, 0,25\% sodium deoxycholate and Protease Inhibitor Cocktail 2 (Sigma-Aldrich)]. Cytoplasmic and nuclear extracts were prepared following a standard protocol (25); trypsinized cells were suspended in lysis buffer to which NP-40 was added at a subsequent step (the supernatant fraction represented the cytoplasmic extract); nuclei were washed and centrifuged, followed by resuspension in extraction buffer and pelleting. Protein extracts were analyzed by a well-established standard western blot procedure (26). Rabbit anti-COX-2 antibody was purchased from Cayman Chemical. Other primary antibodies are indicated in the immunofluorescence staining.
Statistical analysis. Data are expressed as mean \pm SEM and analyzed with ANOVA. P $\leq 0.05$ was considered statistically significant.

\section{Results}

p-Ibuprofen prevents AOM-induced colon cancer. AOM-induced ACF at week 20 and colon tumors at week 40 as shown in Fig. 2A. Histology of tumors shows well-differentiated adenocarcinoma. As shown in Table I and Fig. 2B, compared to vehicle treatment, both $\mathrm{p}$-ibuprofen or ibuprofen significantly reduced the multiplicity of ACF by $31.2 \%$ (54.2 \pm 4.4 vs. $78.8 \pm 11.6$, $\mathrm{p}<0.05)$, or $37.9 \%(48.9 \pm 7.9$ vs. $78.8 \pm 11.6, \mathrm{p}<0.05)$, respectively. However, no difference was observed between groups treated with p-ibuprofen or ibuprofen ( $p>0.05)$. Similarly, as shown in Table I and Fig. 2C, at week 40 treatment with either p-ibuprofen or ibuprofen reduced the multiplicity of colon tumors by $47.2 \%$ $(2.8 \pm 0.52$ vs. $5.3 \pm 0.59$, p $<0.01)$, or $56.6 \%$ ( $2.3 \pm 0.49$ vs. $5.3 \pm 0.59$, $\mathrm{p}<0.01)$, respectively. Again, a significant difference $(\mathrm{p}>0.05)$ was not observed between groups treated with $\mathrm{p}$-ibuprofen and ibuprofen (Table I and Fig. 2D). Furthermore, pathological changes were not detected in heart, lung, liver, stomach and kidney tissues. These results suggest that phospho-modification did not significantly enhance the inhibitory effect of ibuprofen in AOM-induced colon cancer in rats.

Phospho-modification of ibuprofen reduces GI toxicity. As shown in Fig. 3A, a high dose of ibuprofen $(670 \mathrm{mg} / \mathrm{kg})$ administered to rats by gavage for 7 days led to stomach ulcerations 
A

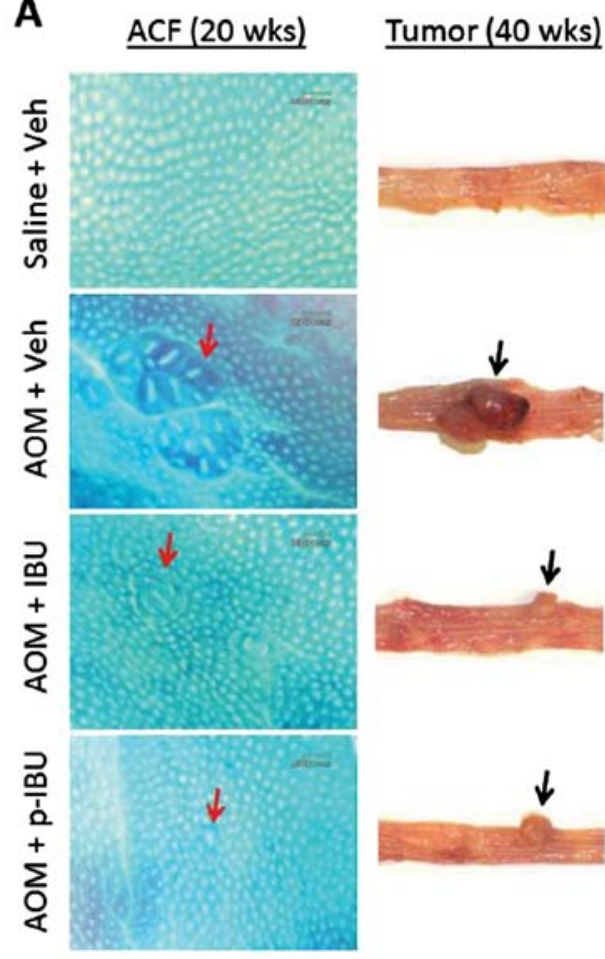

$\underline{H \& E}$

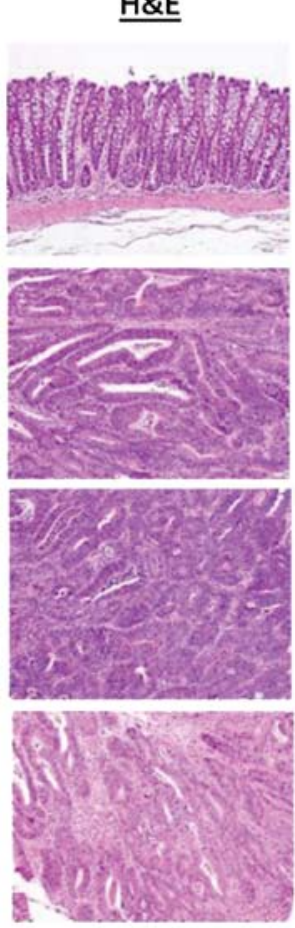

B

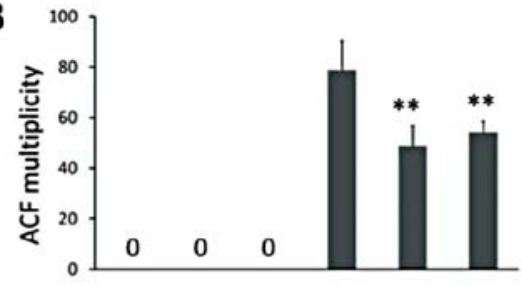

C

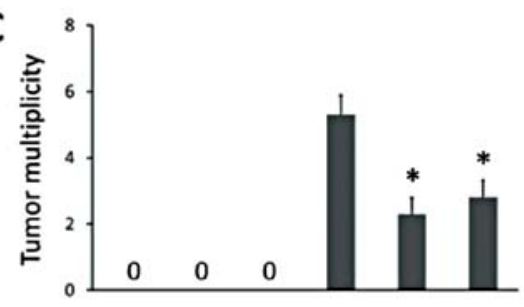

D

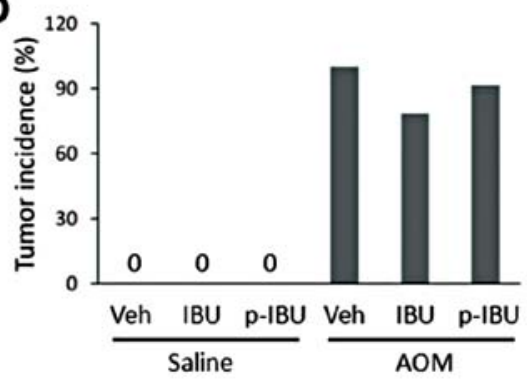

Figure 2. p-IBU inhibits AOM-induced colonic ACF multiplicity and tumor multiplicity in rats. (A) The number of ACFs or tumors per animal was counted in various treatment groups as indicated above. The results show that the number of ACFs and tumors in the colon of AOM treated rats was greatly reduced following treatment with IBU and $\mathrm{p}-\mathrm{IBU}\left({ }^{* *} \mathrm{p}<0.05\right.$ or ${ }^{*} \mathrm{p}<0: 01$, Student's t-test). Dissected colon in descending order: saline + control diet showing no tumors; AOM + control diet showing the presence of tumors (arrows); AOM + diet supplemented with IBU showing reduced number of tumors and; AOM + diet supplemented with p-IBU showing reduced number of tumors. (B) ACF multiplicity; (C) tumor multiplicity; and (D) tumor incidence.

A

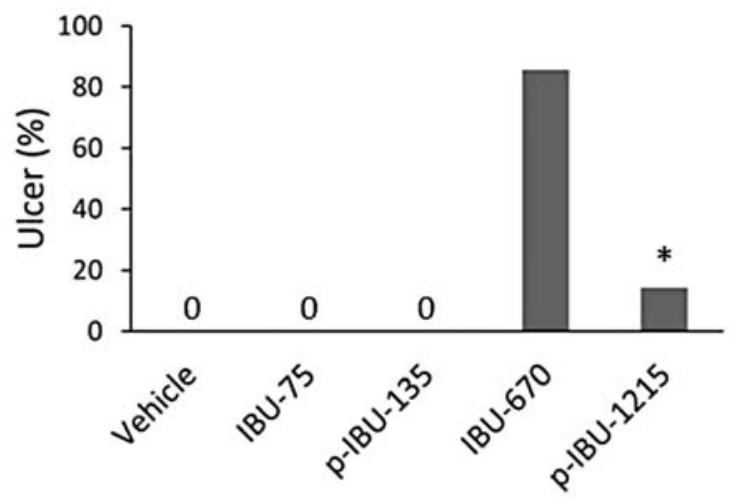

B
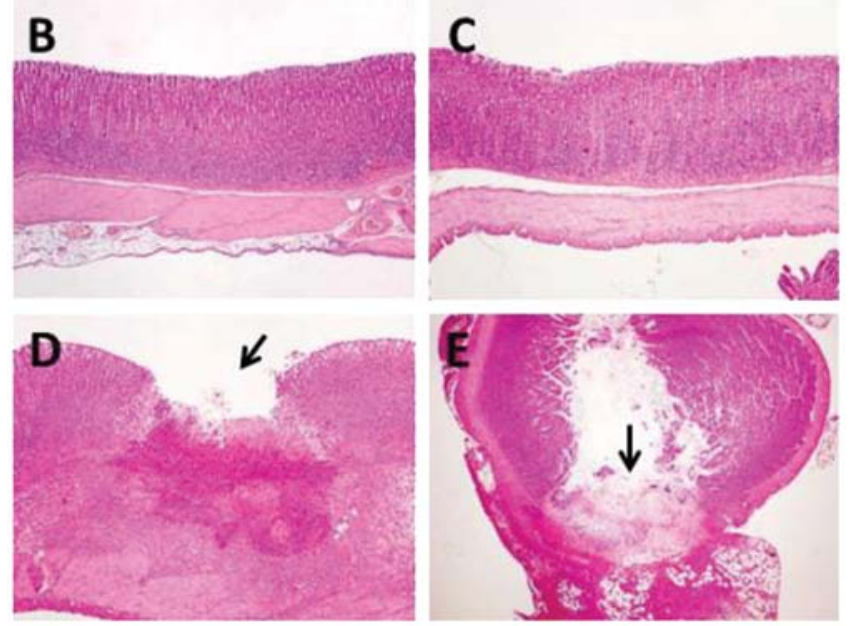

in $85.7 \%$ (6 out of 7) of rats; whereas, an equal molar dose of p-ibuprofen $(1,215 \mathrm{mg} / \mathrm{kg})$ caused stomach ulceration in only $14.3 \%$ ( 1 out of 7 ) of rats. The modification of ibuprofen with the phospho-moiety remarkably reduced its GI side-effect $(p<0.01)$. All animals with stomach ulcers also exhibited ulcerations in the small intestine. Histologically, the typical ulcer appeared with the hiatus of mucosa and ulcerative tissue in the bottom of the ulcer (Fig. 3D). Some of the ulcers exhibited inflammation and perforation (breaking through the wall) in both stomach and intestine (Fig. 3B-E). A low dose of both p-ibuprofen and ibuprofen did not lead to ulceration in either stomach or intestine. There was no obvious pathological change in heart, liver, lung and kidney. These results demonstrate that, whereas the phospho-modification of ibuprofen did not enhance ibuprofen's inhibitory effect on AOM-induced colon cancer in rats, p-ibuprofen significantly reduced the GI toxicity of ibuprofen.

Figure 3. p-IBU reduces toxic GI side effect in rats. Small intestines were dissected and examined for ulceration. (A) A high dose of IBU $(670 \mathrm{mg} /$ $\mathrm{kg}$ ) administered by gavage for 7 days led to stomach ulceration in $85.7 \%$ of rats; whereas, an equal molar dose of p-IBU $(1,215 \mathrm{mg} / \mathrm{kg})$ caused stomach ulceration in only $14.3 \%$ of rats ( $\mathrm{p}<0.01)$. (B) Immunohistochemical staining representative of intestines without ulceration from vehicle-treated rats; (C) representative intestines without ulceration from rats treated with low doses of IBU or p-IBU; (D) representative intestines with typical ulcerations observed with high doses of IBU or p-IBU and; (E) representative intestines with inflammation and perforation observed with high doses of IBU. 
Table I. Inhibition of AOM-induced colonic ACF and tumor multiplicity in rats by p-IBU.

\begin{tabular}{|c|c|c|c|c|c|c|}
\hline \multirow[t]{2}{*}{ Diet } & \multicolumn{2}{|c|}{ Control } & \multicolumn{2}{|c|}{ IBU } & \multicolumn{2}{|c|}{ p-IBU } \\
\hline & Saline $^{a}$ & $\mathrm{AOM}^{\mathrm{a}}$ & Saline $^{a}$ & $\mathrm{AOM}^{\mathrm{a}}$ & Saline $^{a}$ & $\mathrm{AOM}^{\mathrm{a}}$ \\
\hline \multicolumn{7}{|l|}{20 Weeks } \\
\hline Weight & $447 \pm 10.60$ & $423 \pm 9.45$ & $416 \pm 6.11$ & $406 \pm 118.91$ & $420 \pm 6.97$ & $400 \pm 8.14$ \\
\hline ACFs & 0 & $78.8 \pm 11.6$ & 0 & $48.9 \pm 7.9$ & 0 & $54.2 \pm 4.4$ \\
\hline Tumors & 0 & $3.3 \pm 0.72$ & 0 & $1.3 \pm 0.31$ & 0 & $1.7 \pm 0.42$ \\
\hline \multicolumn{7}{|l|}{40 Weeks } \\
\hline Weight & $467 \pm 7.97$ & $434 \pm 11.19$ & $431 \pm 15.43$ & $432 \pm 8.84$ & $455 \pm 5.49$ & $458 \pm 12.33$ \\
\hline ACFs & 0 & $34 \pm 5.17$ & 0 & $35 \pm 4.05$ & 0 & $45 \pm 3.68$ \\
\hline Tumors & 0 & $5.3 \pm 0.59$ & 0 & $2.3 \pm 0.49$ & 0 & $2.8 \pm 0.52$ \\
\hline
\end{tabular}

${ }^{\mathrm{a} A v e r a g e} \pm$ SE. P-values $(\mathrm{ACF} / 20$ weeks): control to IBU, $\mathrm{p}<0.009$; control to $\mathrm{p}$-IBU, $\mathrm{p}<0.046$; and IBU to $\mathrm{p}$-IBU, $\mathrm{p}<0.216$. $\mathrm{P}$-values (tumor/40 weeks): control to IBU, $\mathrm{p}<0.002$; control to $\mathrm{p}$-IBU, $\mathrm{p}<0.030$; and IBU to $\mathrm{p}$-IBU, $\mathrm{p}<0.152$.

A

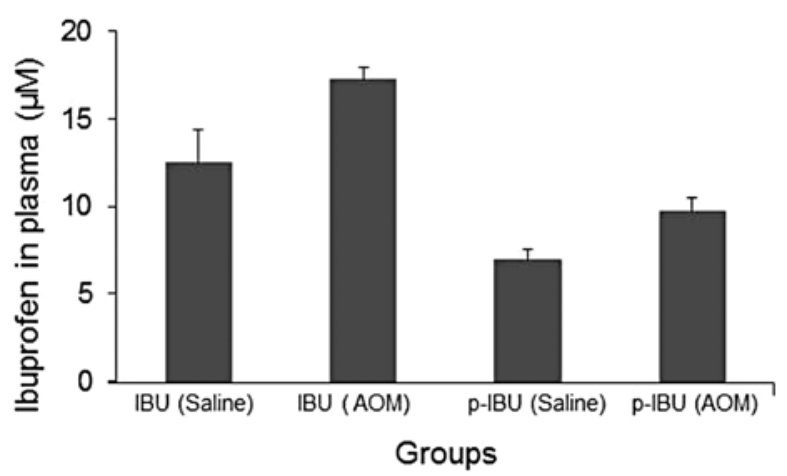

B

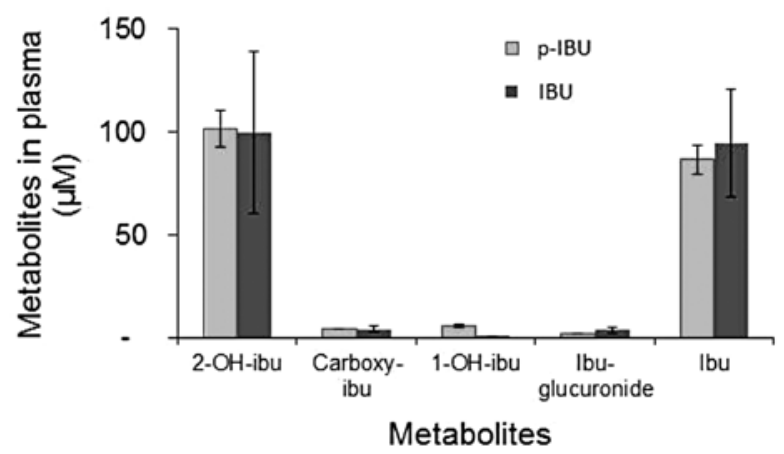

Figure 4. Pharmacokinetics of p-IBU. (A) Detection of IBU in the plasma of rats treated with IBU or p-IBU in the diet for 20 weeks. (B) Plasma level of the metabolites of IBU (2-OH-ibuprofen, carboxy-ibuprofen, 1-OH-ibuprofen, and ibuprofen-glucuronide). These results are comparable to levels seen in the plasma of rats on the same diet for 40 weeks or gavaged with low or high doses of the drug for 7 days.

Pharmacokinetics. As shown in Fig. 4A, with continuous administration of ibuprofen or p-ibuprofen in the diet for 20 weeks, ibuprofen can be detected in the plasma of both treatment groups. The plasmic level of ibuprofen in animals fed a diet with p-ibuprofen is lower than that of animals fed a diet of ibuprofen. Both diet groups (p-ibuprofen and ibuprofen) exhibited the tendency of a higher plasmic ibuprofen level in AOM-treated animals as compared to saline control animals. However, no statistical difference was noted. These trends were comparable in the case where rats were on the same diet for 40 weeks. Intact p-ibuprofen was not detectable in the plasma of animals fed a diet consisting of or gavaged with p-ibuprofen. As seen in Fig. 4B, the metabolite of ibuprofen, 2-OH-ibuprofen, was detectable at a similar level as intact ibuprofen in both groups fed a diet of p-ibuprofen $(102 \mu \mathrm{M})$ or ibuprofen $(99 \mu \mathrm{M})$. Other metabolites were detected at very low levels, including carboxy-ibuprofen (3 and $3 \mu \mathrm{M}$ ), 1-OH-ibuprofen (4 $\mu \mathrm{M}$, undetectable) and ibuprofen-glucuronide (1 and $1 \mu \mathrm{M}) ; 20$ weeks and 40 weeks, respectively.

p-Ibuprofen inhibits COX-2 and PGE $E_{2}$ in macrophages. We evaluated the classic pathway of NSAIDs-COX-2 expression in macrophages. Our results showed that LPS highly induced COX-2 levels and that this effect was completely blocked by both ibuprofen and p-ibuprofen (Fig. 5A). These results suggest that phospho-modification did not alter the property of ibuprofen in inhibiting COX-2 expression.

As seen in Fig. 5B, both ibuprofen and p-ibuprofen significantly suppressed $\mathrm{PGE}_{2}$ production by $84.1 \%(1.7 \pm 0.5$ vs. $10.7 \pm 1.1, \mathrm{p}<0.01)$ and $77.4 \%(2.4 \pm 1.3$ vs. $10.7 \pm 1.1, \mathrm{p}<0.01)$ as compared to LPS-treated control, respectively. However, no significant difference between ibuprofen and p-ibuprofen ( $p>0.05$ ) was observed. This result is consistent with the observed inhibition of COX-2, suggesting that phospho-modification does not decrease the ability of ibuprofen to suppress $\mathrm{PGE}_{2}$ synthesis.

p-Ibuprofen suppresses $\beta$-catenin nuclear translocation and $N F-\kappa B$ activation. As shown in Fig. 6A, exposure to the carcinogen $\mathrm{AOM}$ induced $\beta$-catenin cytoplasmic accumulation and nuclear translocation. These effects were reduced by both p-ibuprofen and ibuprofen. The presence of phosphorylated $\mathrm{NF}-\kappa \mathrm{B}$ subunit p65 indicates NF- $\kappa \mathrm{B}$ activation. By immunohistochemistry analysis (Fig. 6A), p-ibuprofen and not ibuprofen inhibited phosphorylation of $\mathrm{p} 65$ (NF- $\kappa \mathrm{B}$ activation). This in vivo observation was confirmed by an in vitro study. As seen in Fig. 6B, treatment with both p-ibuprofen and ibuprofen 


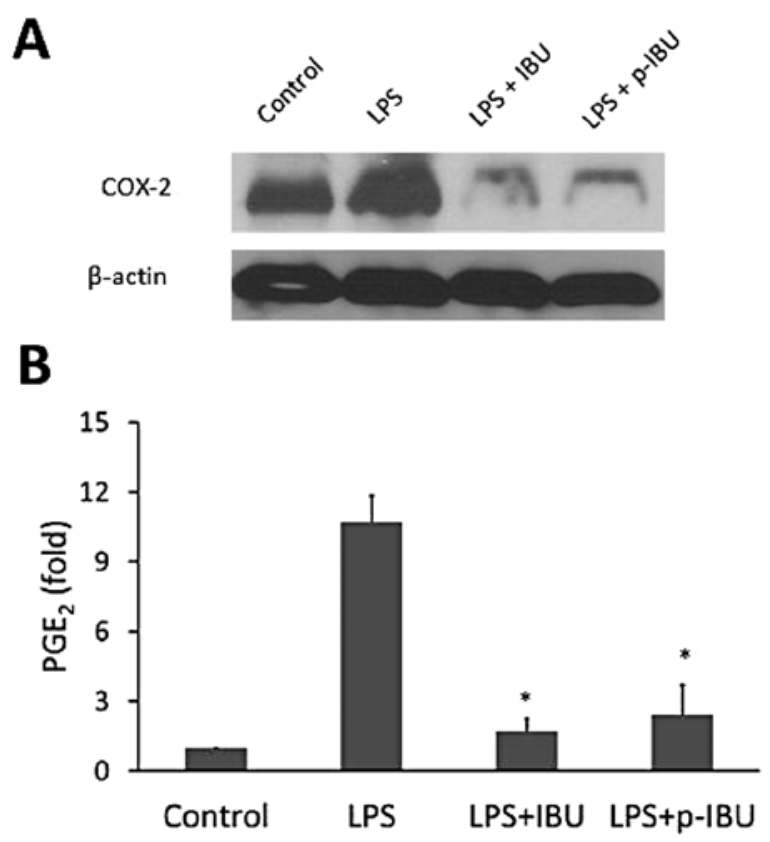

Figure 5. p-IBU inhibits COX-2 and $\mathrm{PGE}_{2}$ in macrophages. RAW 264.7 macrophages were pre-treated with IBU or p-IBU, $130 \mu \mathrm{M}$ for $12 \mathrm{~h}$, then incubated overnight with LPS (100 ng/ml). (A) Western blot analysis demonstrates that induction of COX-2 levels by LPS was completely blocked by both IBU and p-IBU. (B) Evaluation by ELISA demonstrated that both IBU and p-IBU significantly suppressed $\mathrm{PGE}_{2}$ production $(\mathrm{p}<0.01)$ compared to LPS-treated control. markedly decreased $\beta$-catenin levels in the nuclear extracts of HCT116 cells as compared to control (vehicle-treated). Interestingly, $\mathrm{p}$-ibuprofen inhibited the nuclear translocation of the NF- $\mathrm{KB}$ subunit $\mathrm{p} 65$ (NF- $\mathrm{KB}$ activation), but this inhibitory effect was not observed for ibuprofen. This additional inhibitory effect in NF-kB activation may explain why the lower plasmic level of ibuprofen after treatment with p-ibuprofen exhibited a similar tumor inhibitory effect with ibuprofen-treated group.

\section{Discussion}

The modification of existing NSAIDs is significant for developing novel drugs in cancer prevention. To date, there have been no reports indicating that modified ibuprofen possesses increased anticancer activity and reduced GI toxic side effects. For example, Shanbhag et al (27) modified ibuprofen by esterification and amidation with various groups. These modified agents exhibited less anti-inflammatory activity, but only ibuprofen- $\mathrm{O}\left(\mathrm{CH}_{2}\right) 2 \mathrm{~N}\left(\mathrm{CH}_{3}\right) 2 \mathrm{HCl}$ and ibuprofen- $\mathrm{NHCH}_{2} \mathrm{COOH}$ showed decreased GI toxic side effects when compated to the parent molecule. However, our group developed a novel phospho-butanol-modified ibuprofen that exhibits a markedly higher anti-inflammatory efficacy in vivo (21) and anticancer activity in vitro and in xenograft models $(19,20)$ compared with its parent compound ibuprofen. Respectively, this study showed that phospho-modified ibuprofen significantly reduced the GI
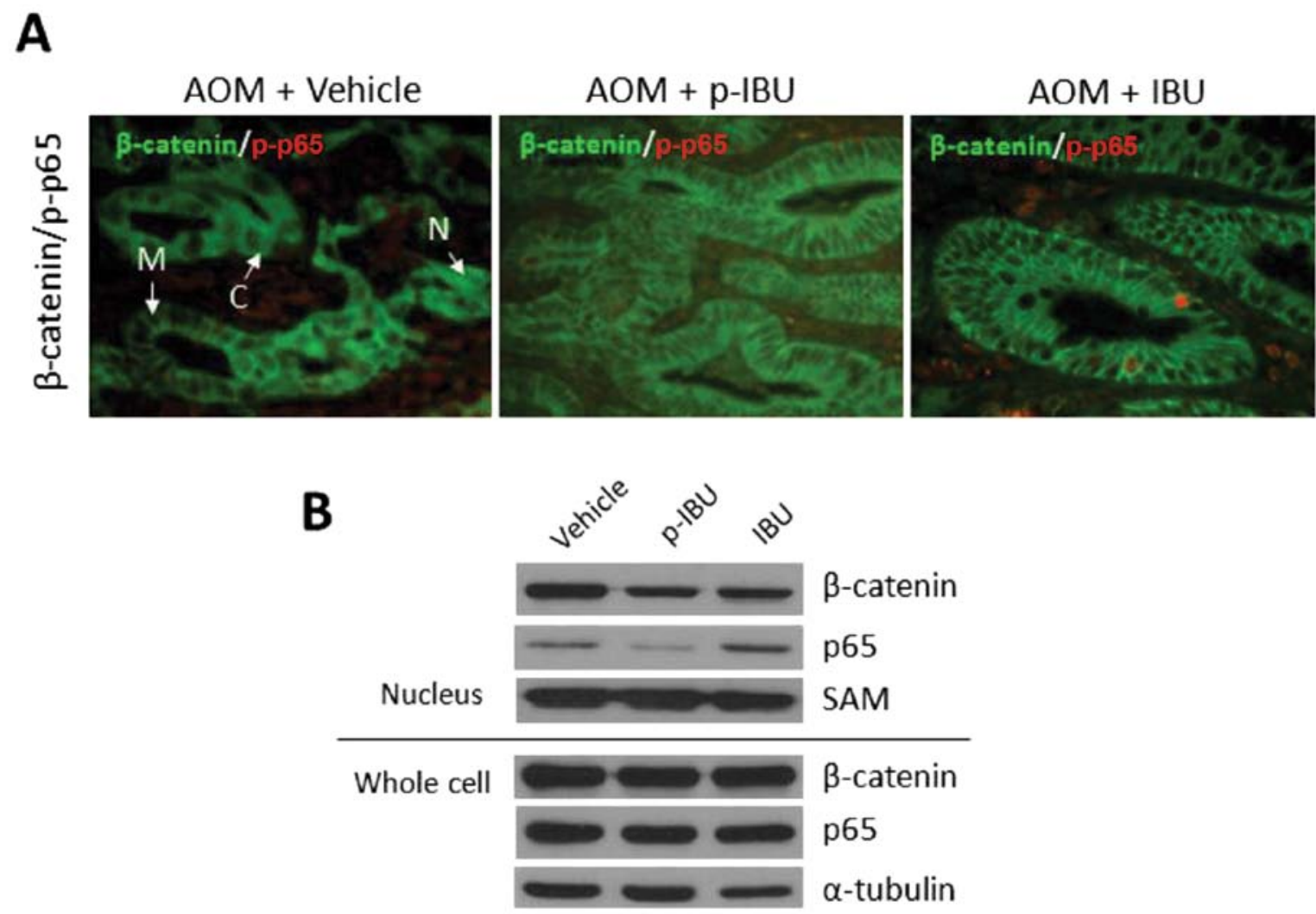

Figure 6. p-IBU inhibits $\beta$-catenin nuclear translocation and NF- $\kappa \mathrm{B}$ activation in cancer cells. (A) Paraffin-embedded sections from rat AOM in vivo study (40 weeks) were prepared for immunohistochemical analysis as described in Materials and methods. p-IBU and IBU reduced AOM induced $\beta$-catenin cytoplasmic accumulation and nuclear translocation. p-IBU inhibited nuclear translocation of the NF- $\mathrm{KB}$ subunit p65. M, membrane; C, cytoplasmic; N, nuclear. (B) Western Blot analysis (in vitro analysis) using nuclear extracts of HCT116 cells demonstrated that both p-IBU and IBU markedly decreased $\beta$-catenin levels. p65 levels were reduced in cells treated with p-IBU. 
toxic side effect compared to the parent ibuprofen. In addition, this compound inhibited AOM-induced colonic ACF and tumor multiplicity in rats in an inhibitory manner similar to the parent compound ibuprofen. This study also shows that this modification significantly reduces the GI toxic side effect associated with the unmodified parent, ibuprofen. p-Ibuprofen inhibits AOM-induced colonic ACF and tumor multiplicity in rats with a potency that is comparable to ibuprofen. As the PK results show, ibuprofen was released into the blood of animals after administration with p-ibuprofen. However, this level is slightly lower when compared to direct ibuprofen administration. This may explain why p-ibuprofen is able to retain the anticancer properties of ibuprofen.

For decades, the mechanisms by which NSAIDs prevent cancer have focused on cyclooxygenase (COX) inhibition $(28,29)$. Recently, COX-2 has been shown to be upregulated in various carcinomas and to have a central role in tumorigenesis (30,31). The classical NSAIDs are not selective and inhibit both COX-1 and COX-2, which results in the inhibition of prostaglandin and thromboxane synthesis and reduced inflammation. This mode of action also causes an adverse effect, irritation of the gastric mucosa, as prostaglandins are considered to have a protective role in the gastrointestinal tract. NSAIDs that have been engineered to selectively inhibit COX-2, such as celecoxib and rofecoxib, cause much less gastric irritation but may increase the risk of heart attack and thrombosis as a result of the increase of thromboxane unbalanced by prostacyclin. In the current study, phospho-modification greatly reduced the GI ulcerogenicity of ibuprofen even when a high dose (9 times regular dose) was used in rats. This was considered to result from both the reduced irritation of free carboxylic group and the inhibition of synthesis of gastrointestinal $\mathrm{PGE}_{2}$ and $\mathrm{PGI}_{2}$ (32-34). Consistent with these findings, our results also showed that, like the parent ibuprofen, p-ibuprofen retained the ability to inhibit COX-2 and $\mathrm{PGE}_{2}$ synthesis. We did not detect additional toxic effect of p-ibuprofen in heart, lung, liver or kidney of rats treated with both regular and high doses; thereby, suggesting that p-ibuprofen is a potential novel drug for long-term use in cancer prevention.

COX inhibition is not the only mechanism by which NSAIDs act. Increasing evidence has shown that COX-independent pathways are involved in the mechanism of action of NSAIDs, especially in cancer prevention via inhibition of cell cycle progression (35-38), induction of apoptosis $(39,40)$, antiangiogenesis $(41,42)$, the mTOR signaling pathway $(43)$, direct gene alteration (44), oxidative phosphorylation in mitochondria $(45,46)$, the induction of nitro oxide radicals $(47)$, and the $\mathrm{NF}-\kappa \mathrm{B}$ signaling pathway $(26,48)$. Further investigation of COX-independent pathways is necessary in order to gain a complete understanding of the mechanism by which NSAIDs prevent cancer. In this study, we show that both ibuprofen and phospho-modified ibuprofen significantly inhibit $\beta$-catenin nuclear translocation both in vivo and in vitro. This finding is consistent with the results reported by Maier et al (49). Our preliminary results show that p-ibuprofen significantly inhibits $N F-\kappa B$ activation in a human colon cancer cell line. $\mathrm{NF}-\kappa \mathrm{B}$, as a master transcriptional regulator of inflammatory response, may be involved in the mechanism of carcinogenesis $(50,51)$. Normally $N F-\kappa B$ is bound to an inhibitor, $I-\kappa B$, in the cytoplasm. To activate the signaling pathway, an $\mathrm{I}-\kappa \mathrm{B}$ kinase (IKK) is phosphorylated and activated. The activated IKK degrades the NF- $\mathrm{NB}$ inhibitor I- $\kappa \mathrm{B}$ (canonical pathway) or p100 (non-canonical pathway) and releases p65/p50 or RelB/p52 dimers (activated subunit forms of $N F-\kappa B$ ) to the nucleus. These proteins then regulate gene transcription for cell survival, proliferation, and inflammation. We will perform additional studies to explore how mechanistically p-ibuprofen activates $\mathrm{NF}-\kappa \mathrm{B}$ signaling pathway.

In summary, phospho-modification of ibuprofen remarkably reduces its GI toxic side effects while allowing it to retain the anti-inflammatory and anticancer activities of its parent compound. In addition to COX-2 mechanism, both ibuprofen and phospho-modified ibuprofen may inhibit the $\beta$-catenin signaling pathway and may suppress NF- $\kappa \mathrm{B}$ activation in cancer cells. Taken together, these results solidify our hypothesis that p-ibuprofen is a potential effective novel drug for long-term use in colon cancer prevention.

\section{Acknowledgements}

This study was supported by grants K01CA106604 and R01CA140487. We would like to thank Dr Gang Xie for is assistance with HPLC analysis.

\section{References}

1. Johnson CC, Hayes RB, Schoen RE, Gunter MJ and Huang WY; PLCO Trial Team: Non-steroidal anti-inflammatory drug use and colorectal polyps in the Prostate, Lung, Colorectal, and Ovarian Cancer Screening Trial. Am J Gastroenterol 105: 2646-2655, 2010.

2. Harris RE, Beebe-Donk J and Alshafie GA: Similar reductions in the risk of human colon cancer by selective and nonselective cyclooxygenase-2 (COX-2) inhibitors. BMC Cancer 8: 237, 2008.

3. Harris RE, Beebe-Donk J, Doss H and Burr Doss D: Aspirin, ibuprofen, and other non-steroidal anti-inflammatory drugs in cancer prevention: a critical review of non-selective COX-2 blockade (Review). Oncol Rep 13: 559-583, 2005.

4. Cioli V, Putzolu S, Rossi V and Corradino C: A toxicological and pharmacological study of ibuprofen guaiacol ester (AF 2259) in the rat. Toxicol Appl Pharmacol 54: 332-339, 1980.

5. Venuti MC, Young JM, Maloney PJ, Johnson D and McGreevy K: Synthesis and biological evaluation of omega(N,N,N-trialkylammonium)alkyl esters and thioesters of carboxylic acid nonsteroidal antiinflammatory agents. Pharm Res 6: 867-873, 1989.

6. Samara E, Avnir D, Ladkani D and Bialer M: Pharmacokinetic analysis of diethylcarbonate prodrugs of ibuprofen and naproxen. Biopharm Drug Dispos 16: 201-210, 1995.

7. Abordo EA, Bowden K, Huntington AP and Powell SL: Prodrugs. Part 3. 2-Formylphenyl esters of indomethacin, ketoprofen and ibuprofen and 6-substituted 2-formyl and 2-acylphenyl esters of aspirin. Farmaco 53: 95-101, 1998.

8. Mahfouz NM, Omar FA and Aboul-Fadl T: Cyclic amide derivatives as potential prodrugs II: N-hydroxymethylsuccinimide-/isatin esters of some NSAIDs as prodrugs with an improved therapeutic index. Eur J Med Chem 34: 551-562, 1999

9. Kahns AH, Jensen PB, Mork N and Bundgaard H: Kinetics of hydrolysis of indomethacin and indomethacin ester prodrugs in aqueous solution. Acta Pharm Nord 1: 327-336, 1989.

10. Wang LF, Chiang HN and Wu PC: Kinetics and hydrolysis mechanism of polymeric prodrugs containing ibuprofen, ketoprofen, and naproxen as pendent agents. J Biomater Sci Polym Ed 13: 287-299, 2002.

11. Peng YS, Lin SC, Huang SJ, et al: Chondroitin sulfate-based anti-inflammatory macromolecular prodrugs. Eur J Pharm Sci 29: 60-69, 2006.

12. Zhao X, Tao X, Wei D and Song Q: Pharmacological activity and hydrolysis behavior of novel ibuprofen glucopyranoside conjugates. Eur J Med Chem 41: 1352-1358, 2006. 
13. Kourounakis PN, Tsiakitzis K, Kourounakis AP and Galanakis D: Reduction of gastrointestinal toxicity of NSAIDs via molecular modifications leading to antioxidant anti-inflammatory drugs. Toxicology 144: 205-210, 2000.

14. Galanakis D, Kourounakis AP, Tsiakitzis KC, et al: Synthesis and pharmacological evaluation of amide conjugates of NSAIDs with L-cysteine ethyl ester, combining potent antiinflammatory and antioxidant properties with significantly reduced gastrointestinal toxicity. Bioorg Med Chem Lett 14: 3639-3643, 2004.

15. Yeh RK, Chen J, Williams JL, et al: NO-donating nonsteroidal antiinflammatory drugs (NSAIDs) inhibit colon cancer cell growth more potently than traditional NSAIDs: a general pharmacological property? Biochem Pharmacol 67: 2197-2205, 2004

16. Kashfi K, Ryan Y, Qiao LL, et al: Nitric oxide-donating nonsteroidal anti-inflammatory drugs inhibit the growth of various cultured human cancer cells: evidence of a tissue type-independent effect. J Pharmacol Exp Ther 303: 1273-1282, 2002.

17. Williams JL, Borgo S, Hasan I, Castillo E, Traganos F and Rigas B: Nitric oxide-releasing nonsteroidal anti-inflammatory drugs (NSAIDs) alter the kinetics of human colon cancer cell lines more effectively than traditional NSAIDs: implications for colon cancer chemoprevention. Cancer Res 61: 3285-3289, 2001

18. Mattheolabakis G, Nie T, Constantinides PP and Rigas B Sterically stabilized liposomes incorporating the novel anticancer agent phospho-ibuprofen (MDC-917): preparation, characterization, and in vitro/in vivo evaluation. Pharm Res 29 : 1435-1443, 2012.

19. Sun Y, Huang L, Mackenzie GG and Rigas B: Oxidative stress mediates through apoptosis the anticancer effect of phosphononsteroidal anti-inflammatory drugs: implications for the role of oxidative stress in the action of anticancer agents. J Pharmacol Exp Ther 338: 775-783, 2011.

20. Xie G, Sun Y, Nie T, et al: Phospho-ibuprofen (MDC-917) is a novel agent against colon cancer: efficacy, metabolism, and pharmacokinetics in mouse models. J Pharmacol Exp Ther 337: 876-886, 2011.

21. Huang L, Mackenzie G, Ouyang N, et al: The novel phosphonon-steroidal anti-inflammatory drugs, OXT-328, MDC-22 and MDC-917, inhibit adjuvant-induced arthritis in rats. Br J Pharmacol 162: 1521-1533,2011.

22. Wong CC, Cheng KW, Xie G, et al: Carboxylesterases 1 and 2 hydrolyze phospho-NSAIDs: relevance to their pharmacological activity. J Pharmacol Exp Ther 340: 422-432, 2012.

23. Piazza GA, Keeton AB, Tinsley HN, et al: A novel sulindac derivative that does not inhibit cyclooxygenases but potently inhibits colon tumor cell growth and induces apoptosis with antitumor activity. Cancer Prev Res (Phila) 2: 572-580, 2009.

24. Bird RP: Observation and quantification of aberrant crypts in the murine colon treated with a colon carcinogen: preliminary findings. Cancer Lett 37: 147-151, 1987.

25. Natarajan K, Singh S, Burke TR Jr, Grunberger D and Aggarwal BB: Caffeic acid phenethyl ester is a potent and specific inhibitor of activation of nuclear transcription factor NF-kappaB. Proc Natl Acad Sci USA 93: 9090-9095, 1996

26. Williams JL, Ji P, Ouyang N, Liu X and Rigas B: NO-donating aspirin inhibits the activation of NF-kappaB in human cancer cell lines and Min mice. Carcinogenesis 29: 390-397, 2008.

27. Shanbhag VR, Crider AM, Gokhale R, Harpalani A and Dick RM: Ester and amide prodrugs of ibuprofen and naproxen: synthesis, anti-inflammatory activity, and gastrointestinal toxicity. J Pharm Sci 81: 149-154, 1992.

28. Antonakopoulos $\mathrm{N}$ and Karamanolis DG: The role of NSAIDs in colon cancer prevention. Hepatogastroenterology 54 1694-1700, 2007.

29. Backlund MG, Mann JR and Dubois RN: Mechanisms for the prevention of gastrointestinal cancer: the role of prostaglandin E2. Oncology 69 (Suppl 1): 28-32, 2005.

30. Koki A, Khan NK, Woerner BM, et al: Cyclooxygenase-2 in human pathological disease. Adv Exp Med Biol 507: 177-184, 2002.

31. Koch A, Gustafsson B, Fohlin H and Sorenson S: Cyclooxygenase-2 expression in lung cancer cells evaluated by immunocytochemistry. Diagn Cytopathol 39: 188-193, 2011.

32. Schoen RT and Vender RJ: Mechanisms of nonsteroidal antiinflammatory drug-induced gastric damage. Am J Med 86 449-458, 1989.
33. Mitchell JA and Warner TD: Cyclo-oxygenase-2: pharmacology, physiology, biochemistry and relevance to NSAID therapy. Br J Pharmacol 128: 1121-1132, 1999.

34. Wallace JL and Cirino G: The development of gastrointestinal-sparing nonsteroidal anti-inflammatory drugs. Trends Pharmacol Sci 15: 405-406, 1994.

35. Kardosh A, Blumenthal M, Wang WJ, Chen TC and Schonthal AH: Differential effects of selective COX-2 inhibitors on cell cycle regulation and proliferation of glioblastoma cell lines. Cancer Biol Ther 3: 55-62, 2004.

36. Narayanan BA, Condon MS, Bosland MC, Narayanan NK and Reddy BS: Suppression of N-methyl-N-nitrosourea/testosterone-induced rat prostate cancer growth by celecoxib: effects on cyclooxygenase-2, cell cycle regulation, and apoptosis mechanism(s). Clin Cancer Res 9: 3503-3513, 2003

37. Grosch S, Tegeder I, Niederberger E, Brautigam L and Geisslinger G: COX-2 independent induction of cell cycle arrest and apoptosis in colon cancer cells by the selective COX-2 inhibitor celecoxib. FASEB J 15: 2742-2744, 2001.

38. Maier TJ, Schilling K, Schmidt R, Geisslinger $G$ and Grosch $S$ : Cyclooxygenase-2 (COX-2)-dependent and -independent anticarcinogenic effects of celecoxib in human colon carcinoma cells. Biochem Pharmacol 67: 1469-1478, 2004.

39. Arico S, Pattingre S, Bauvy C, et al: Celecoxib induces apoptosis by inhibiting 3-phosphoinositide-dependent protein kinase-1 activity in the human colon cancer HT-29 cell line. J Biol Chem 277: 27613-27621, 2002.

40. Hsu AL, Ching TT, Wang DS, Song X, Rangnekar VM and Chen CS: The cyclooxygenase-2 inhibitor celecoxib induces apoptosis by blocking Akt activation in human prostate cancer cells independently of Bcl-2. J Biol Chem 275: 11397-11403, 2000.

41. Ostrowski J, Wocial T, Skurzak H and Bartnik W: Do altering in ornithine decarboxylase activity and gene expression contribute to antiproliferative properties of COX inhibitors? $\mathrm{Br}$ J Cancer 88: 1143-1151, 2003.

42. Wei D, Wang L, He Y, Xiong HQ, Abbruzzese JL and Xie K: Celecoxib inhibits vascular endothelial growth factor expression in and reduces angiogenesis and metastasis of human pancreatic cancer via suppression of $\mathrm{Sp} 1$ transcription factor activity. Cancer Res 64: 2030-2038, 2004.

43. Zhang YJ, Bao YJ, Dai Q, et al: mTOR signaling is involved in indomethacin and nimesulide suppression of colorectal cancer cell growth via a COX-2 independent pathway. Ann Surg Oncol 18: 580-588, 2011

44. Wang X, Baek SJ and Eling T: COX inhibitors directly alter gene expression: role in cancer prevention? Cancer Metastasis Rev 30: 641-657, 2011.

45. Petrescu I and Tarba C: Uncoupling effects of diclofenac and aspirin in the perfused liver and isolated hepatic mitochondria of rat. Biochim Biophys Acta 1318: 385-394, 1997.

46. Somasundaram S, Sigthorsson G, Simpson RJ, et al: Uncoupling of intestinal mitochondrial oxidative phosphorylation and inhibition of cyclooxygenase are required for the development of NSAID-enteropathy in the rat. Aliment Pharmacol Ther 14: 639-650, 2000

47. Das S, Khan N, Mukherjee S, et al: Redox regulation of resveratrol-mediated switching of death signal into survival signal. Free Radic Biol Med 44: 82-90, 2008.

48. Vaish V, Tanwar L and Sanyal SN: The role of NF-kappaB and PPARgamma in experimentally induced colorectal cancer and chemoprevention by cyclooxygenase- 2 inhibitors. Tumour Biol 31: 427-436, 2010

49. Maier TJ, Janssen A, Schmidt R, Geisslinger G and Grosch S: Targeting the beta-catenin/APC pathway: a novel mechanism to explain the cyclooxygenase-2-independent anticarcinogenic effects of celecoxib in human colon carcinoma cells. FASEB J 19: 1353-1355, 2005

50. Paul S, DeCastro AJ, Lee HJ, et al: Dietary intake of pterostilbene, a constituent of blueberries, inhibits the beta-catenin/ p65 downstream signaling pathway and colon carcinogenesis in rats. Carcinogenesis 31: 1272-1278, 2010.

51. Onizawa M, Nagaishi T, Kanai T, et al: Signaling pathway via TNF-alpha/NF-kappaB in intestinal epithelial cells may be directly involved in colitis-associated carcinogenesis. Am J Physiol Gastrointest Liver Physiol 296: G850-G859, 2009. 